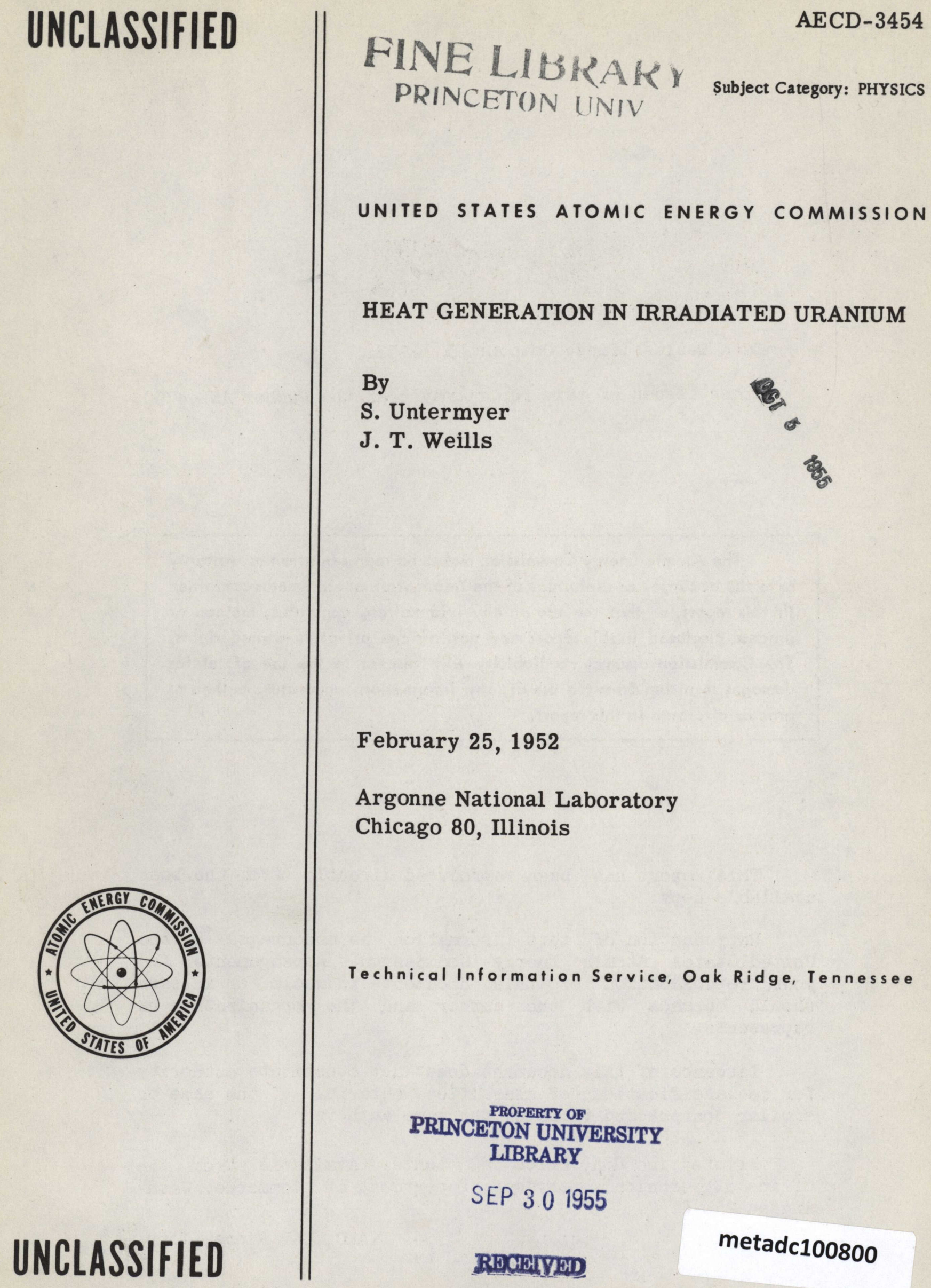


Date Declassified: October 21, 1952.

Other issues of this report may bear the Number ANL- 4790 .

The Atomic Energy Commission makes no representation or warranty as to the accuracy or usefulness of the information or statements contained in this report, or that the use of any information, apparatus, method or process disclosed in this report may not infringe privately-owned rights. The Commission assumes no liability with respect to the use of, or for damages resulting from the use of, any information, apparatus, method or process disclosed in this report.

This report has been reproduced directly from the best available copy.

Reproduction of this information is encouraged by the United States Atomic Fnergy Commission. Arrangements for your republication of this document in whole or in pert should be made with the author and the organization he represents.

Issuance of this document does not constitute authority for declassification of classified material of the same or similar content and title by the same authors.

Printed in USA, Price 20 cents. Available from the office of Technical Services, Department of Commerce, Washington $25, \mathrm{D}$. C. 


\section{ARGONNE NATIONAL LABORATORY \\ P. O. Box 5207 \\ Chicago 80, Illino is}

\section{HEAT GENERATION IN IRRADIATED URANIUM}

by

S. Untermyer and J. T. Weills

February 25, 1952

Operated by The University of Chicago under

Contract W-31-109-eng-38 



\section{HEAT GENERATION IN IRRADIATED URANIUM}

This report presents data on the heat generated in irradiated uranium. Results are presented both as curves and formulae. Data cover the range between $10^{-1}$ and $10^{8}$ seconds.

Heat is produced in uranium from the following causes after a chain reaction is stopped:

1. Fissions from delay neutrons

2. Decay of radioactive fission products

3. Decay of U-239 and $\mathrm{Np}-239$.

The first item becomes insignificant within a few minutes after irradiation. The last item is an appreciable fraction of shutdown heating with natural uranium fuel. The results given in the report do not include a delay neutron contribution since this factor depends upon a particular reactor situation.

Determination of decay heating can be made in two ways:

1. Radiochemical; by measuring the number and energy of disintegrations such as reported in references $3,4,5,6,9,10,11,12$.

2. Calorimetric; by measuring heat produced by radioactive decay such as reported in references $2,7,8,9,13$.

Accurate calorimetric data extend from $10^{4}$ to $5 \times 10^{6}$ seconds after shutdown, including new information given in Appendix I. At shorter times, data obtained in this manner are inaccurate due to thermal lags in apparatus. At longer times, the sensitivity of the equipment is too low.

For long times after shutdown, up to $10^{8}$ seconds, the total beta and gamma decay heating for fission products and $\mathrm{Np}-239$ has been calculated using radiochemical decay data. This is reported in Appendix II by E. P. Steinberg.

At short times, from $1 / 10$ to 20 seconds, only gamma data are available (references $5,6,11$ ). These data are inconsistent in the range 0-3 seconds. Reference 6 has been used in this report as the main source over this range. 
In order to utilize decay heating data, the heat rate must be given a relationship to irradiation time and decay time. By considering fission product decay as a statistical process, Wigner and Way (1) derived expressions which lead to formulae of the type:

$$
\frac{P_{s}}{P_{0}}=A\left\{T_{s}{ }^{-C}-\left(T_{0}+T_{s}\right)^{-C}\right\}
$$

where

$$
\begin{aligned}
& T_{\mathbf{s}}=\text { Time in seconds since operation } \\
& T_{0}=\text { Operation time in seconds } \\
& P_{s}=\text { Rate of heat generation during shutdown } \\
& P_{0}=\text { Rate of heat generation during operation } \\
& A, C \text { are constants }
\end{aligned}
$$

Since it has been found that such formulae represent data quite well, it is convenient and customary to use formulae of this general type.

However, since the formulae as represented above are based on satistical methods, there exist times so short or so long that the radioactive fission products are too few to be treated by these methods and corrections are required to extend the range to these times. A modification to equation (1) to fit experimental data over the entire available range is given below:

$$
\begin{aligned}
\frac{P_{s}}{P_{0}}= & 0.1\left\{\left(T_{s}+10\right)^{-0.2}-0.87\left(T_{s}+2 \times 10^{7}\right)^{-0.2}\right\}-0.1\left\{\left(T_{s}+T_{0}+10\right)^{-0.2}-0.87\right. \\
& \left.\left(T_{s}+T_{0}+2 \times 10^{7}\right)^{-0.2}\right\}
\end{aligned}
$$

Heat from decay of $\mathrm{U}-239$ and $\mathrm{Np}-239$ is included. This formula is plotted on Figure I and can be seen to agree quite well with experimental measurements of references $2,6,8,9$, and 10 . It is expected that the curves have the following accuracy:

$$
\begin{array}{ll}
\text { Under } 1 \text { second } & - \text { large error } \\
1 \text { to } 10^{2} \text { seconds } & - \pm 50 \% \\
10^{2} \text { to, } 10^{4} \text { seconds } & - \pm 30 \% \\
10^{4} \text { to } 10^{6} \text { seconds } & - \pm 10 \% \\
10^{6} \text { to } 10^{8} \text { seconds } & - \pm 50 \%
\end{array}
$$

Equation (2) gives values about 22 per cent higher than found by summing fission product heating from individual yields, energies, and half lives (Appendix 2). This is believed to be good agreement with calorimetric data considering the fundamental uncertainties involved. The shape of equation (2) for long times after shutdown follows the slope of the 
radiochemical data closely, deviating about 7 per cent. Equation (2) in the differential form was used for the comparison:

$$
\frac{d\left(P_{s} / P_{o}\right)}{d T_{s}}=0.02\left\{\left(T_{s}+10\right)^{-1.2}-0.87\left(T_{s}+2 \times 10^{7}\right)^{-1.2}\right\}
$$

An additional set of curves, Figure 2, has been prepared for pure $\mathrm{U}-235$. Contributions from $\mathrm{U}-239$ and $\mathrm{Np}-239$ have been subtracted from equation ( 1 ) using the following expressions:

For the heat produced by U-239 decay -

$$
\frac{P(U-239)}{P_{0}}=0.0025\left\{e^{-\left(\frac{T s}{2040}\right)}-e^{-\left(\frac{T_{s}+T_{0}}{2040}\right)}\right\}
$$

For the heat produced by $\mathrm{Np}-239$ decay -

$$
\frac{P(N p-239)}{P_{0}}=0.0013\left\{e^{-\left(\frac{T_{s}}{290,000}\right)}-e^{-\left(\frac{T_{s}+T_{o}}{290,000}\right)}\right\}
$$

where $P(U-239)=$ rate of heat generation due to $U-239$

$\mathrm{P}(\mathrm{Np}-239)=$ rate of heat generation due to $\mathrm{Np}-239$

Recent data on Np-239 decay modes (see Appendix 2) indicate that the constant in equation (5) may be as high as 0.0023 . The curves of Figure 2 are therefore believed to be conservative for the range of time over $\mathrm{Np}-239$ decay.

\footnotetext{
"Calorimetric data on heat generation in irradiated uranium have been extended to shorter and longer times. In extending these data, the shape of the differential curves was adjusted to coincide with radioactive decay measurements. Differential data on radioactive decay after long cooling periods were based on appendix II, while data for very short periods were based on Ref. 6 , and on supplementary measurements (not reported) which indicated that the shortest lived fission products had an effective half-life of approximately 6 seconds.

The curves for natural uranium are based on irradiations in reactors where the conversion ratio was about 0.8 ."
} 


\section{REFERENCES}

Page

(1) E. P. Wigner and K. Way, Paper 43, National Nuclear Energy Series, Div. IV, Vol. 9 (New York: McGraw - Hill Book Co.,

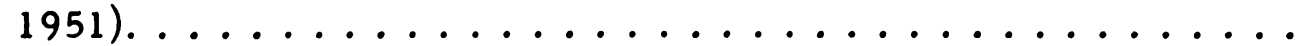

(2) R. A. Day and C. V. Cannon, Paper 41, ibid. ......... 3,4

(3) L. B. Borst, Paper 34, ibid. ................ 3

(4) E. L. Brady and A. Turkevich, CL-697-VIII-C-4........ 3

(5) L. D. P. King, J. A. Hoffman, P. B. Moon, and R. Perry, L. A. 253A (Dec. 7, 1945).................

(6) N. Sugarman, S. Katcoff, B. Finkle, N. Elliott, and J. D. Knight, Paper 37; National Nuclear Energy Series, Div IV, Vol. 9 (New York: McGraw - Hill Book Co., 1951)......... 3, 4

(7) W. K. Alexander, HW $10349 \ldots \ldots \ldots$

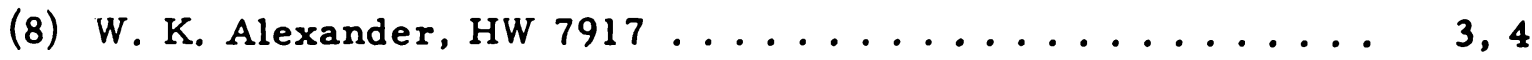

(9) S. Untermyer, Appendix I (herein) .............. 3,4

(10) J. D. Knight, Paper 38, National Nuclear Energy Series, Div. IV, Vol. 9 (New York: McGraw - Hill Book Co., 1951). . 3, 4

(11) J. D. Brolley and M. S. Livingston, LA-1188 (Jan. 15, 1951) . 3

(12) E. P. Steinberg, Appendix II (herein)............. 3

(13) S. E. Beall, ORNL-1075 .................. 3 
$T_{s}$ ${ }^{m}{ }^{2 m}$






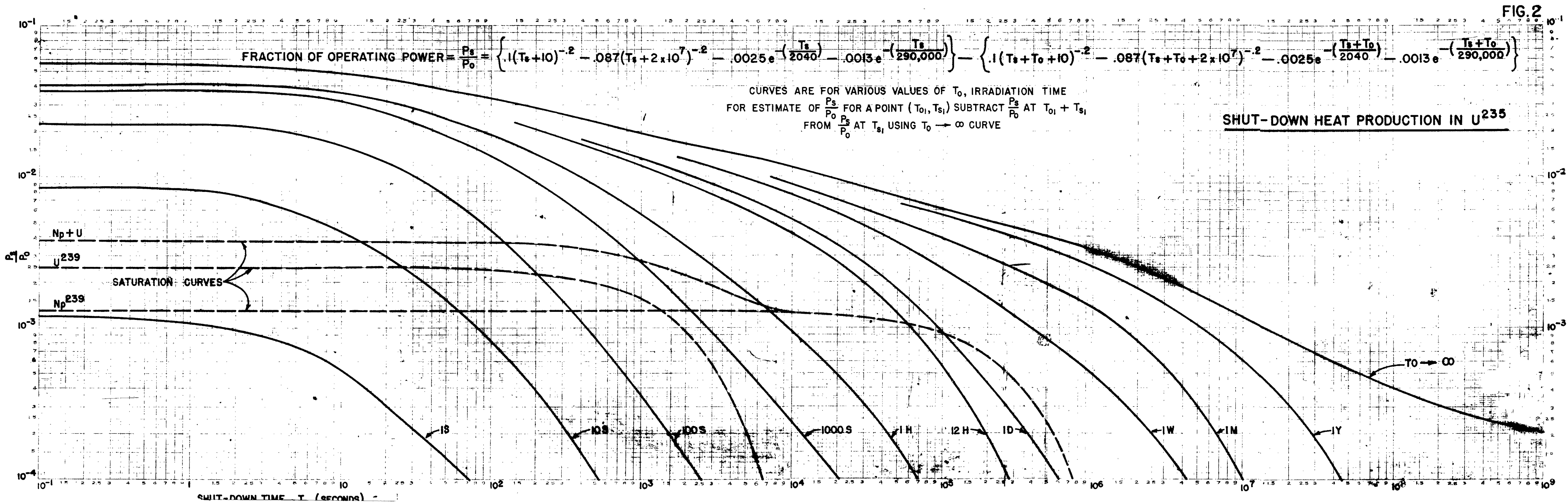




\section{APPENDIX I - A}

(1) A Calorimetric Measurement of Fission Product Heating in a Uranium Rod

Abstract

Apparatus was developed to measure the ratio: $\frac{\text { Heat Production after irradiation }}{\text { Heat Production during irradiation }}$ for a 1 inch diameter uranium rod. At short times after irradiation, the thermal lag of the apparatus did not permit reliable measurements, so auxiliary determinations were made based on beta - gamma activities.

These measurements ignore escape of gammas from the slug, and they include decay energy due to neutron capture in $\mathrm{U}-238$.

Experimental Method

A piece of uranium rod was mounted on one of the prongs of an aluminum fork. The other prong contained a piece of lead.

Heat generated in the uranium, or lead, was conducted along the prongs of the fork, to the point where the prongs joined the large thermal mass, which absorbed the heat from the apparatus.

The prongs of the fork were polished, to minimize loss of heat by radiation, and were further enclosed first by a polished aluminum radiation shield, and finally, in a vacuum chamber.

The entire assembly was then placed in the "goat-hole" of $\mathrm{CP}-3^{\prime}$ in a thermal neutron flux of about $3 \times 10$ inches.

Iron wires were threaded into the aluminum prongs near the point where the uranium and lead samples were attached. These wires formed differential thermo-couple junctions, and the E.M.F. of the junctions indicated the temperature difference between the two prongs. If all the heat was removed by conduction along the prongs, then the E.M.F. from the iron wires would indicate the difference in heat production between a uranium lump and a similar lump of lead. A schematic arrangement of this apparatus is shown on Figure 1, and drawings of the actual experimental setup are shown on Figures 2 and 3. It can be seen that 1 inch diameter slugs were used in these tests. A megavac pump was used to provide about 20 micron vacuum in the chamber. 
The iron wires were brought out to a sensitive galvanometer $(0.1 \mu / \mathrm{mm}$ on a $50 \mathrm{~cm}$ scale). By the use of suitable resistors, the sensitivity of the galvanometer could be varied by a factor of 10 .

The readings of the galvanometer were taken, both during pile operation and at various times after shutdown, following operation for various periods.

The ratio, $\frac{\text { Galvanometer reading after shutdown }}{\text { Galvanometer reading during operation }}$, was calculated. Results are shown on Figure 4. After corrections were applied, this ratio gave the desired result of $\frac{\text { Heat production after shutdown }}{\text { Heat production during operation }}$

During operation, the galvanometer read about $4300 \mathrm{~mm}$ equivalent deflection. Since this galvanometer could not be read closer than $1 \mathrm{~mm}$, an error in reading of 0.023 per cent of full power would be expected. Even larger errors might result from spurious E.M.F.'s at junctions, and so forth. Every effort was made to reduce junction errors by thermal insulation and choice of materials, yet it is estimated that errors as large as 0.05 per cent are possible, due to these causes.

\section{Corrections to Measurements}

Three types of corrections must be applied to measurements:

(1) Thermal Lag - During the initial period after shutdown, the apparatus will read "high" until the temperature gradients in the in the prongs attain the equilibrium value. The error due to thermal lag seems to have a "half life" of about 5 minutes. An attempt was made to eliminate some of this error by making a run after 10 minutes irradiation, and subtracting the results of this run from the results of other runs, all of which used exposures of at least 5 days duration.

Previous measurements have shown that the heat $30 \mathrm{~min}$ utes after shutdown is less than 20 per cent as much for 10 minutes exposure as for 5 day exposure. For longer times, and longer exposures, this method of correction is somewhat better, however, as shown on Figure 5; corrections during the first two hours operation are large, and results are correspondingly uncertain.

(2) Correction for Intermittent Pile Operation - Since $\mathrm{CP}-3^{\prime}$ normally operated only about 5 days each week, a correction had to be applied to convert results to a continuous operation basis. 
The pile normally operated 5 days continuously before shutdown, so the corrections applied to the long lived decay products only. To compensate for this intermittent operation, the results from long exposures were increased, so that the difference between the heat production, and heat production for 5 day exposure, was augmented by a factor of $7 / 5$. In general, this correction is so small that it could not introduce serious errors into results.

\section{(3) Correction for Gamma Ray Escape and Capture -} A fraction of the gamma rays escape, and do not heat the rod. Thus, results are typical of a 1 inch rod, but higher values would be expected for thicker rods. This correction might amount to 20 per cent more heat shortly after shutdown, with thicker rods. The correction becomes small at later times, as gammas become softer, and a smaller portion escape. No attempt was made to apply this correction to results. Similarly, it was assumed that heating of lead slug by the pile gammas was comparable to heating of the uranium slug by pile gammas. This is certainly not true, but since both slugs are fairly thick to most gammas, the lead slug does serve to reduce error due to pile gamma heating. That this error is small was indicated by the 10 minute exposure curve, which dropped down toward zero as expected. If many pile gammas were present, an effect on this curve would be observed. Moreover, it was found that physically removing the apparatus from the pile did

not change shutdown readings; thus pile gammas do not appear to have much effect on results.

Results

Figure 5 shows results obtained with irradiations of 16 hours, 5 days, and 3 months. These results have been corrected for thermal lag and for intermittent pile operation. 
APPENDIX I - B

(2) Radioactive Decay of Fission Products

Supplementary measurements were made to determine the shape of the fission product decay curves for the period between 20 seconds and 10 hours after shutdown. Samples were indicated in the CP-3' rabbit, and activity was measured with an ion chamber and a recording vibrating reed electrometer. Beta activity was measured using small, unshielded samples, while gamma activity was measured using a $6 \mathrm{~mm}$ Fe shield. U-235 was used for short irradiations ( 2 seconds exposure). For longer irradiations, and longer times, natural uranium samples were used. These were exposed wrapped in 2 mil natural uranium foils, so that the major surface contribution to resonance absorption of U-238 was eliminated.

Various exposures were combined into a single set of curves for 30 minutes exposure, one curve representing gammas, the other representing betas. Assuming these curves represented equal heat production at 30 seconds after shutdown, the curves were added, and normalized to calorimetric data at several hours after shutdown. In this way, the shape of the fission product heating curve shortly after shutdown was determined. Results are shown on Figure 6.

It is interesting to observe the "bulge" on the beta decay curve at 23 minutes (corresponding to the decay of U-239). This "bulge" evidently corresponds to about 20 per cent of the total heat generation at this time. The beginning of a later "bulge" in the beta decay curve is also evident. This probably results from the decay of $\mathrm{Np}-239$ ( $2 \cdot 3$ day). It appears that this activity may be responsible for a large fraction of the total heat production at $2 \cdot 3$ days after shutdown.

In this experiment, it was assumed that beta and gamma energies were substantially constant. For this reason, results may be considerably in error. 


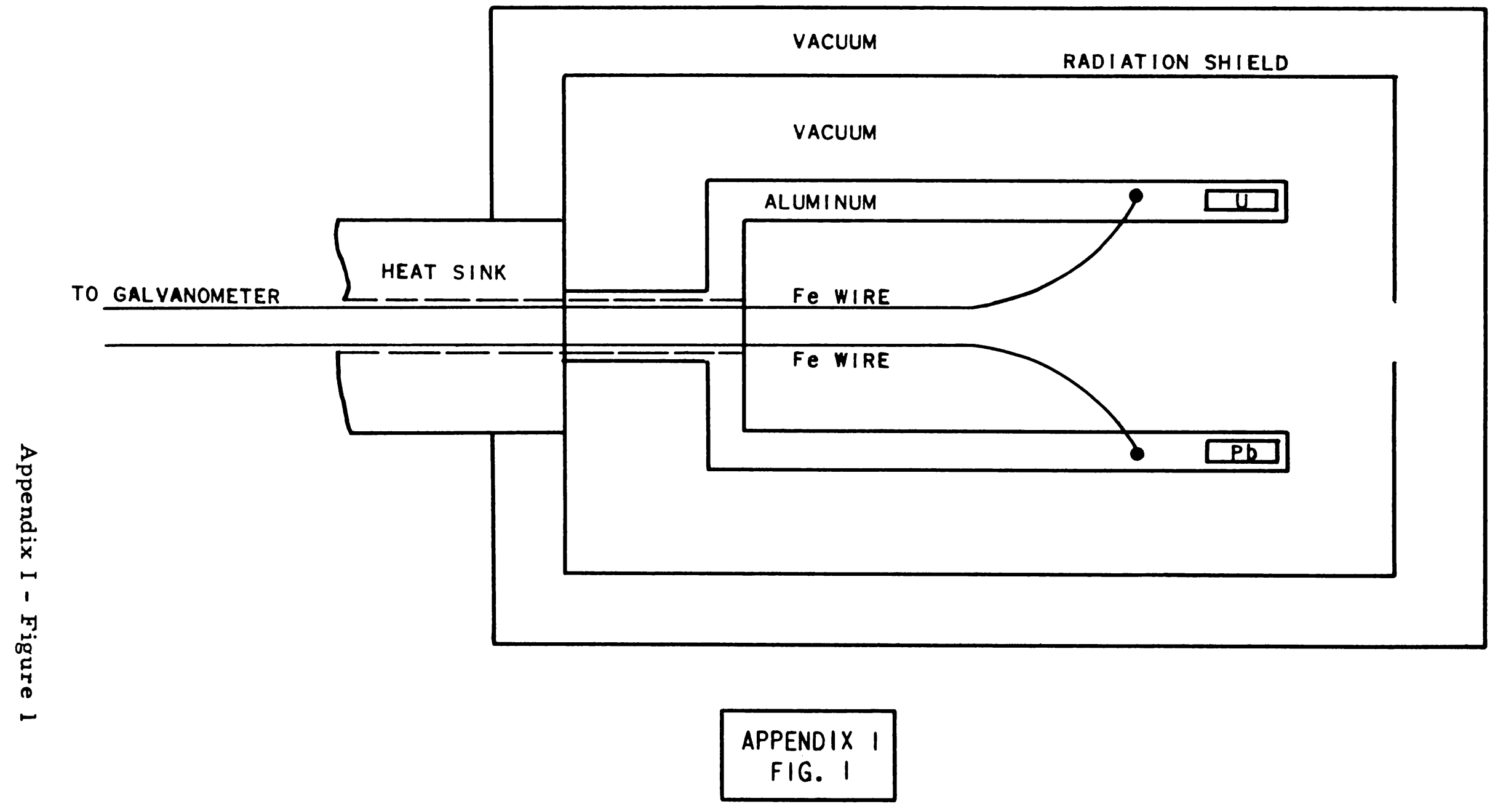

NU-G-292-A 


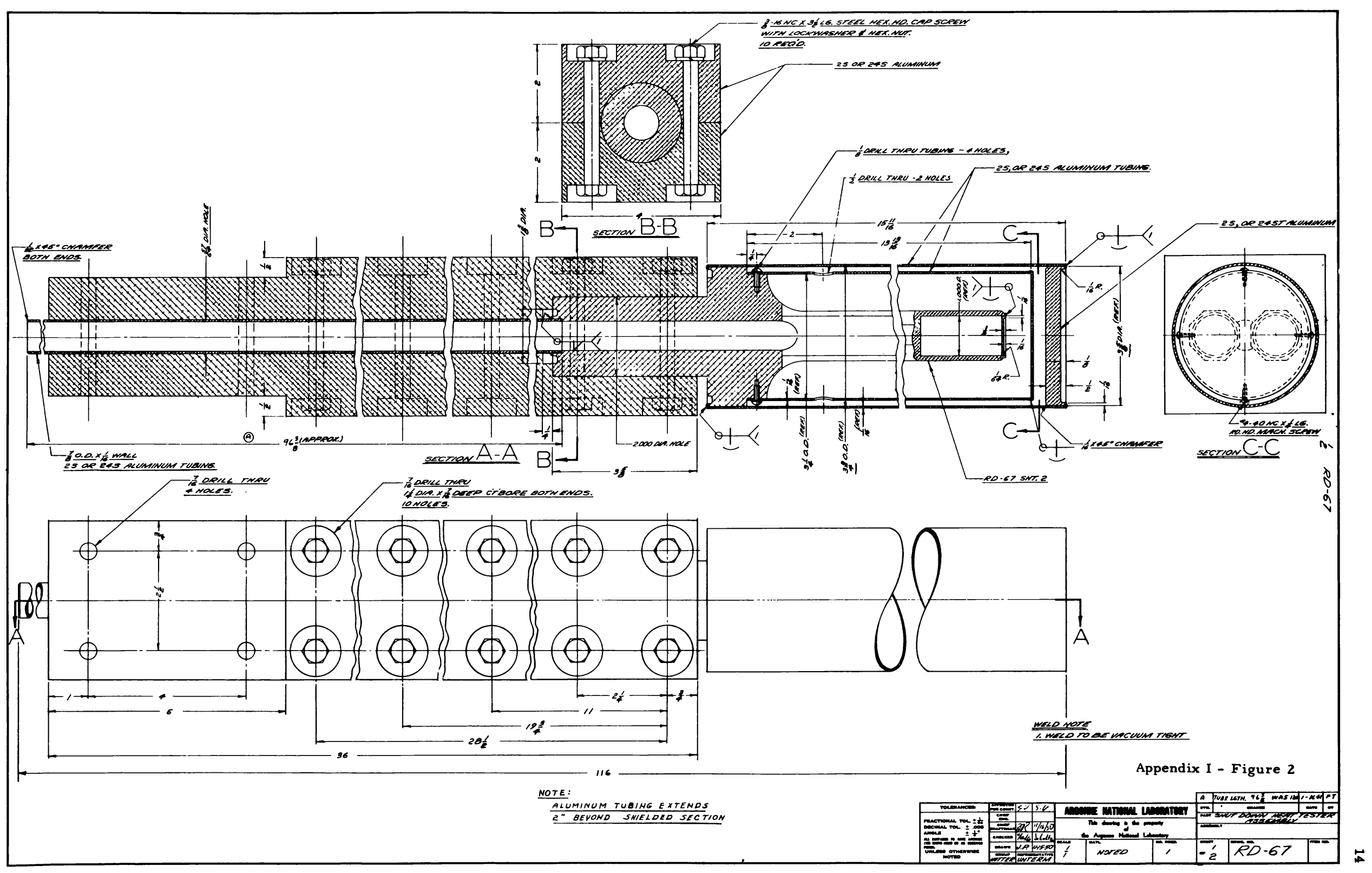




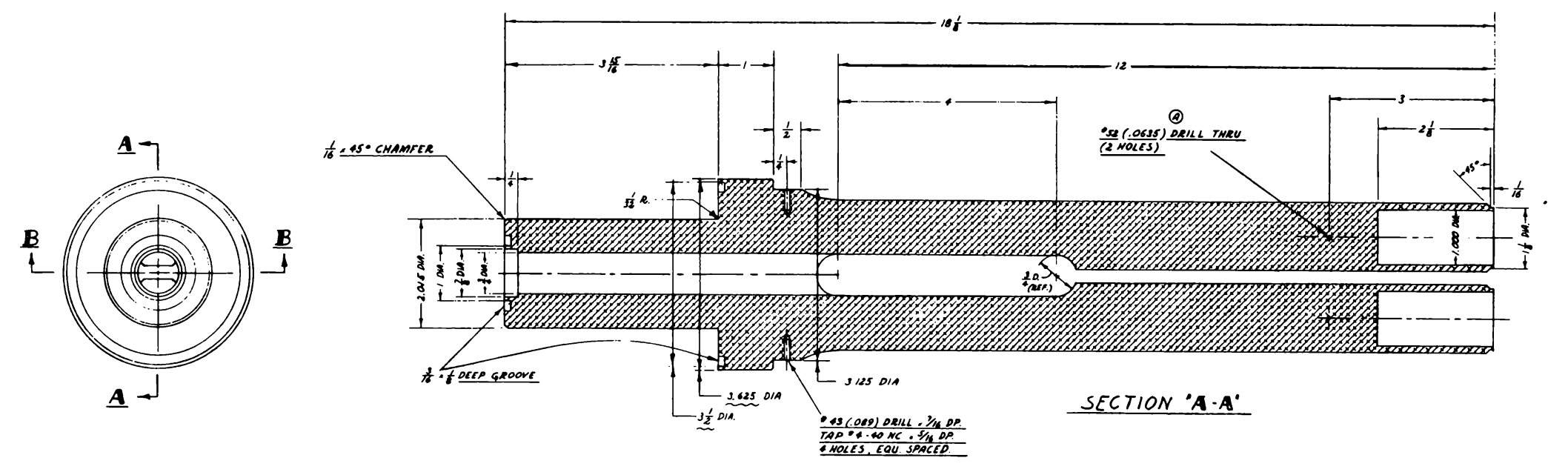

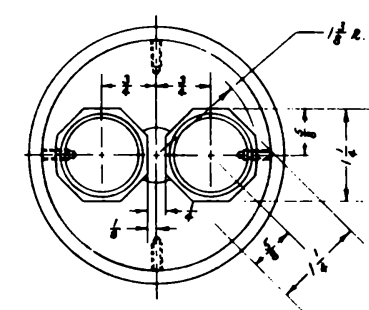

VIEW 'C.C'

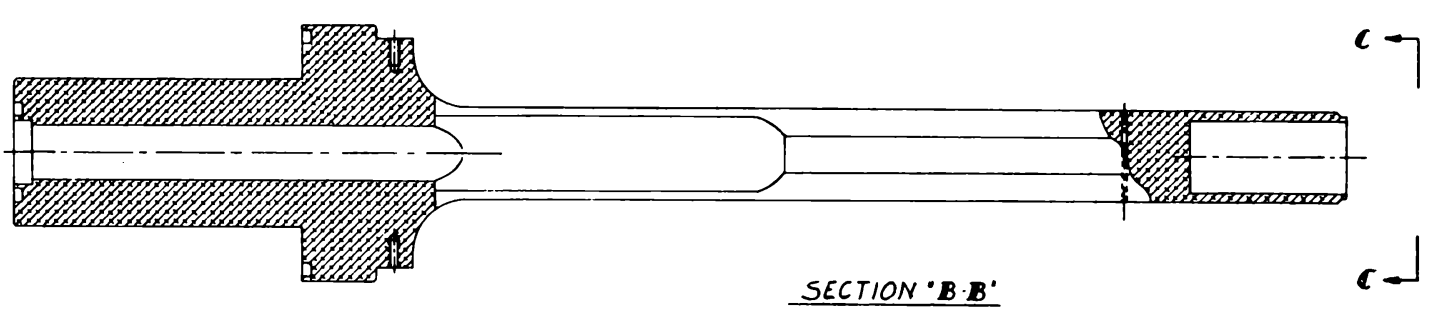

Appendix I - Figure 3 


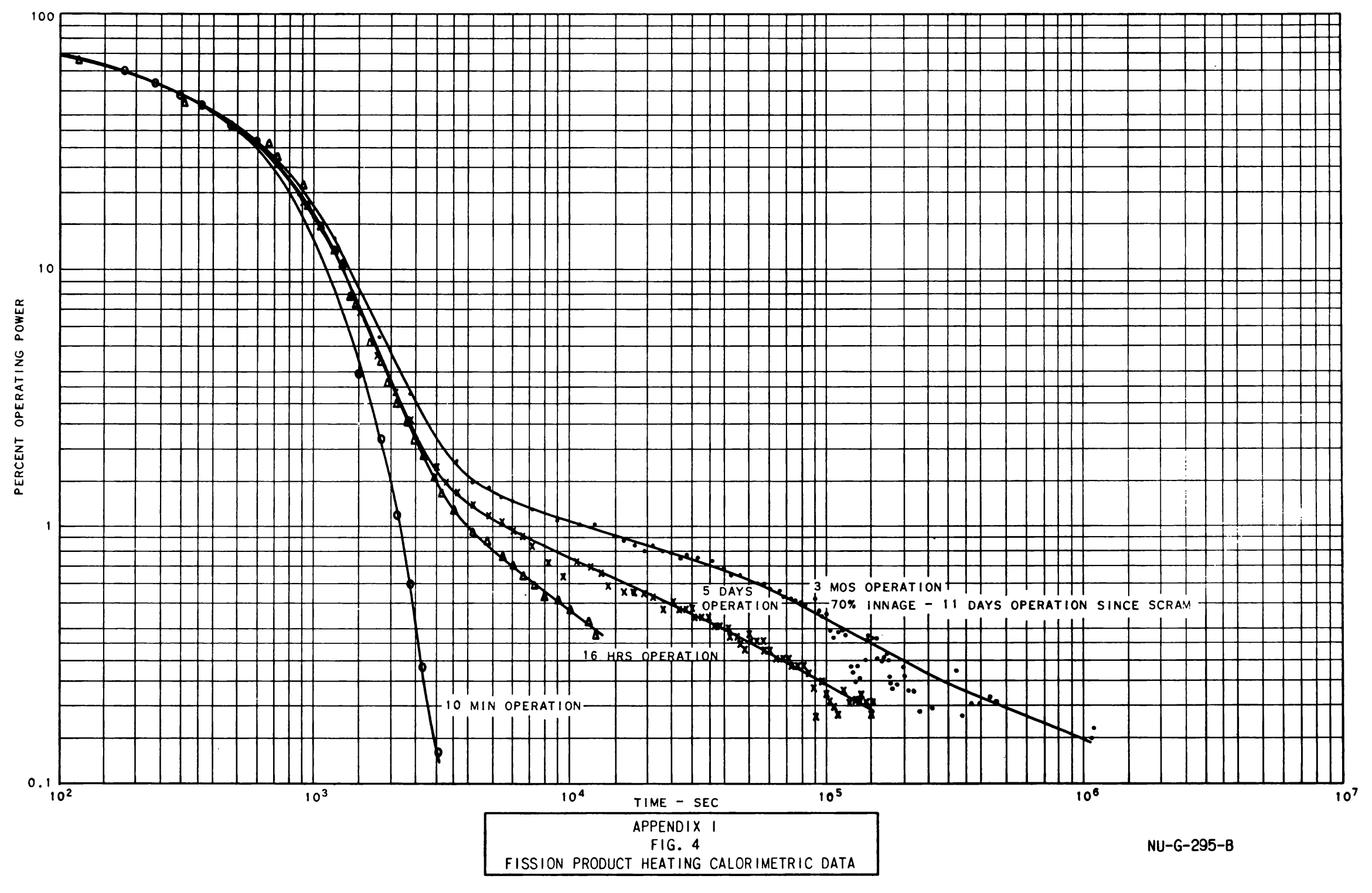

Appendix I - Figure 4 


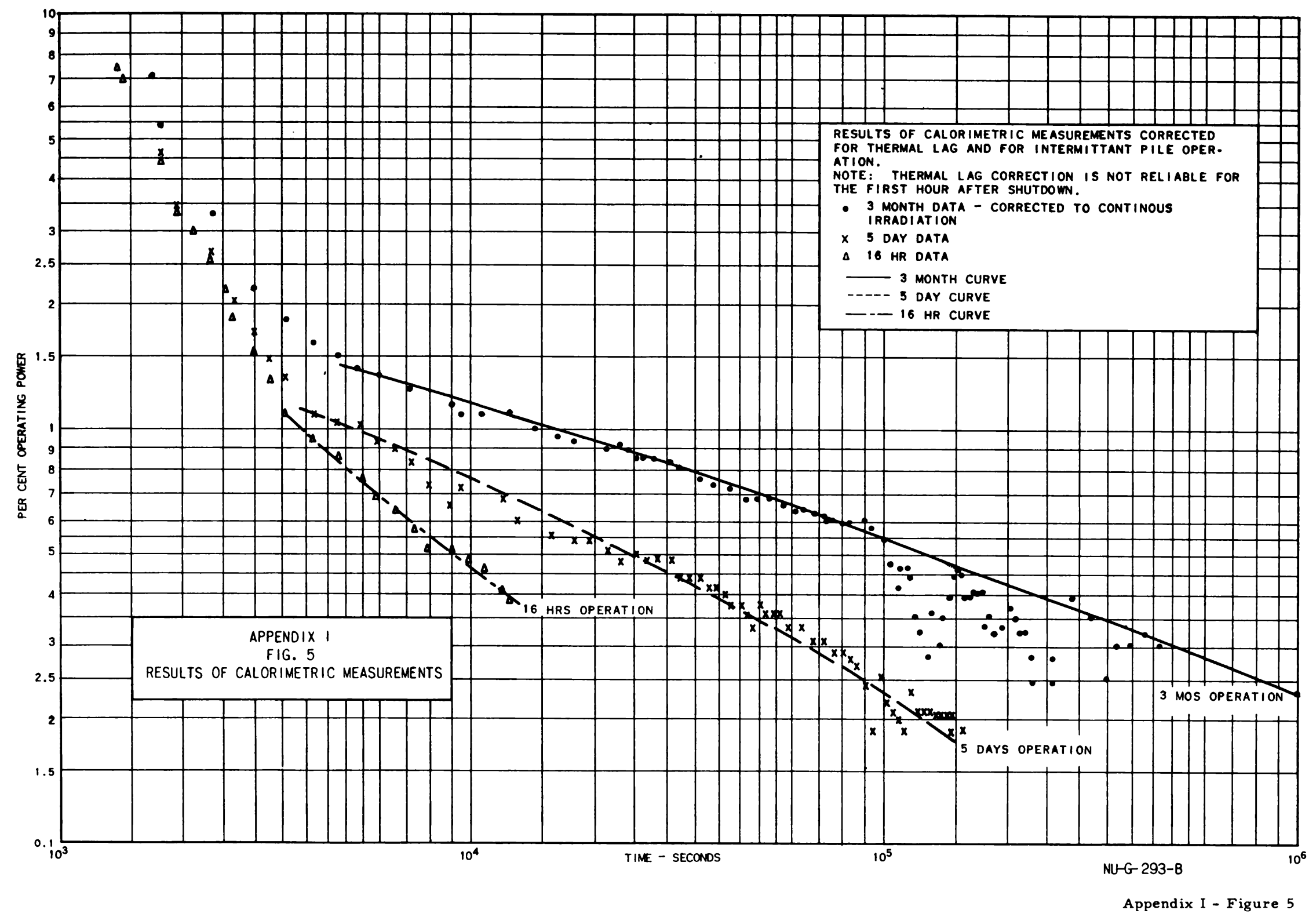




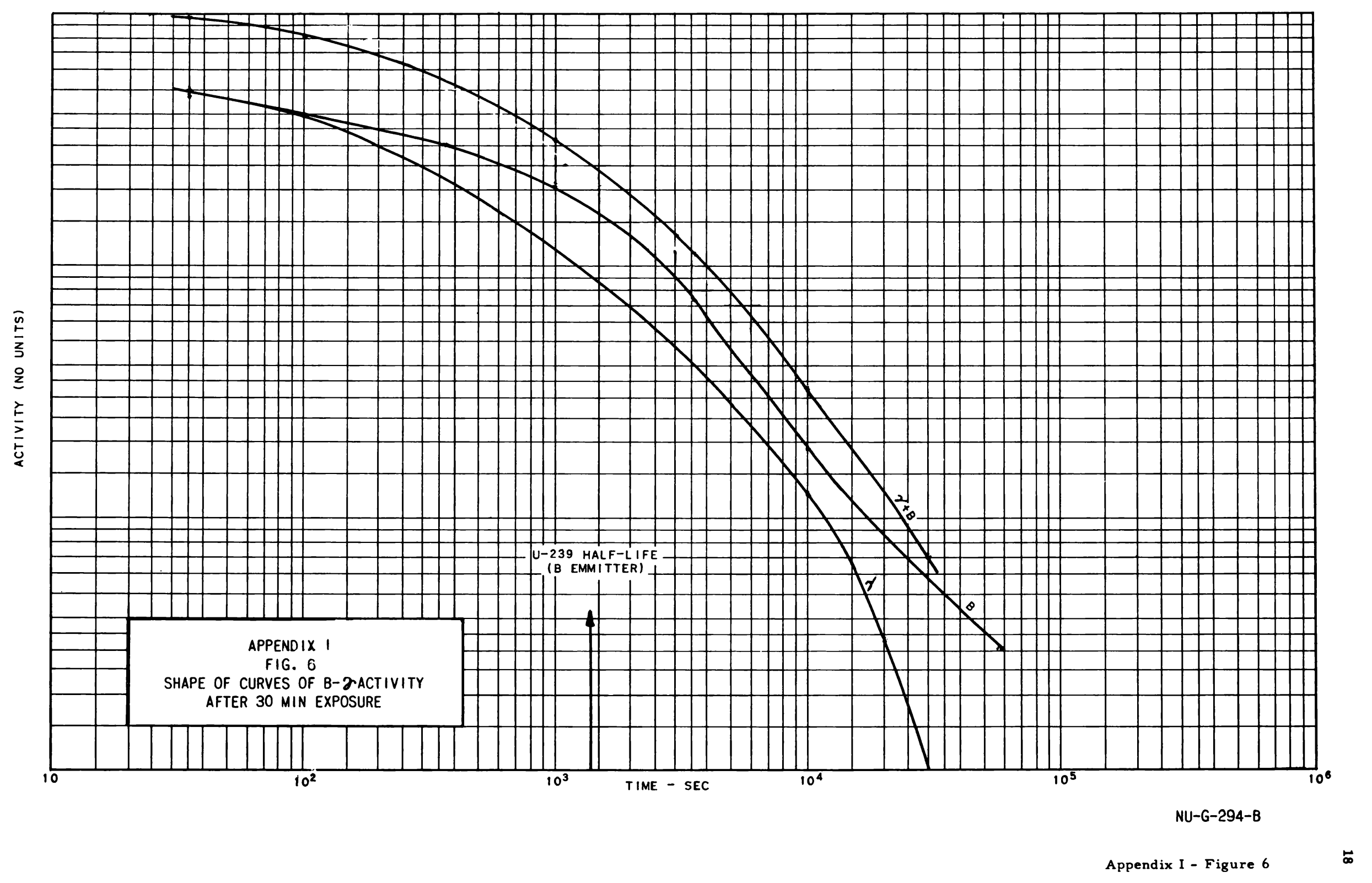




\title{
APPENDIX if
}

\section{POWER DECAY OF FISSION PRODUCTS}

\author{
(Instantaneous irradiation, 1 day -5 years decay)
}

by

\section{E. P. Steinberg, Argonne National Laboratory}

The power dissipation of gross fission products has been calculated as a function of time (from one day to five years) after their instantaneous production. The calculations are based on the relative activities of all fission product nuclides which contribute $>1$ per cent of the total activity at any time as calculated from their known half lives, genetic relationships, and fission yields. Such a compilation of the activity of fission products is given by Hunter and Ballou (Report ADC-65) and these data were used in the present calculations.

The determination of the energy per disintegration for each of the fission products is based on the best available information on their decay schemes and beta and gamma energies. The average beta energy was taken to be $0.4 \mathrm{E}_{\max }$. Since many internal conversion coefficients have not been determined as yet, it was felt advisable to include the $e^{-}$and $X$-ray energies in the total gamma disintegration energy, that is, the decay is represented as taking place 100 per cent by gamma emission. This, of course, has no effect on the total energy of disintegration but only on the particular division of the total into the fraction emitted as electrons and the fraction emitted as electromagnetic radiation. In these calculations, then, the former is somewhat smaller and the latter somewhat larger than the corresponding true fraction.

During the irradiation of normal $U$ with neutrons, the capture in $\mathrm{U}-238$, giving rise to $\mathrm{U}-239$ and subsequently $\mathrm{Np}-239$ and $\mathrm{Pu}-239$ represents a significant addition to the activity of the fission products of $U-235$. The decay scheme of $2 \cdot 3 \mathrm{~d} \mathrm{~Np}-239$ has not yet been completely elucidated; however, on the basis of spectrometer data taken in this laboratory [cf. J. Huizenga, L. Magnusson, M. Freedman and F. Wagner, Phys. Rev. $\underline{84}$, 1264 (1951)] and information received from J. J. Howland of Brookhaven National Laboratory, the following decay data was utilized: beta rays of $0.719 \mathrm{Mev}(3$ per cent), $0.651 \mathrm{Mev}(2.5$ per cent), $0.441 \mathrm{Mev}$ (56 per cent), $0.336 \mathrm{Mev}$ (38 per cent) and gamma rays of $0.277 \mathrm{Mev}$ (94 per cent), $0.067 \mathrm{Mev}(2.5$ per cent), and $0.105 \mathrm{Mev}$ (38 per cent). These data give an average beta energy of $0.165 \mathrm{Mev}$ and a total gamma energy of $0.302 \mathrm{Mev}$. A value of 0.9 for $\sigma_{C}(U-238) / \sigma_{f}(U-235)$ was used in the calculation of the initial $\mathrm{Np}-239$ activity. 
The calculations are presented in tabular form giving the total fission product plus $\mathrm{Np}-239$ watts/fission and the derivative of the fraction of operating power as a function of shutdown time.

\begin{tabular}{c}
$\begin{array}{c}\text { Shutdown } \\
\text { Time } \\
(\mathrm{sec})\end{array}$ \\
\hline $8.64 \times 10^{4}$ \\
$2.16 \times 10^{5}$ \\
$4.32 \times 10^{5}$ \\
$8.64 \times 10^{5}$ \\
$2.16 \times 10^{6}$ \\
$4.32 \times 10^{6}$ \\
$8.64 \times 10^{6}$ \\
$2.16 \times 10^{7}$ \\
$3.16 \times 10^{7}$ \\
$6.32 \times 10^{7}$ \\
$9.48 \times 10^{7}$ \\
$1.264 \times 10^{8}$ \\
$1.58 \times 10^{8}$
\end{tabular}

\begin{tabular}{c} 
Total Watts/Fission \\
(F. P. $+\mathrm{Np}-239)$ \\
\hline $6.80 \times 10^{-19}$ \\
$2.43 \times 10^{-19}$ \\
$1.03 \times 10^{-19}$ \\
$3.78 \times 10^{-20}$ \\
$1.10 \times 10^{-20}$ \\
$4.77 \times 10^{-21}$ \\
$1.88 \times 10^{-21}$ \\
$4.75 \times 10^{-22}$ \\
$2.51 \times 10^{-22}$ \\
$7.97 \times 10^{-23}$ \\
$3.92 \times 10^{-23}$ \\
$2.46 \times 10^{-23}$ \\
$1.82 \times 10^{-23}$
\end{tabular}

$\frac{d\left(P_{s} / P_{0}\right)}{d T_{s}}\left(\sec ^{-1}\right)$

$2.12 \times 10^{-8}$

$7.57 \times 10^{-9}$

$3.22 \times 10^{-9}$

$1.18 \times 10^{-9}$

$3.44 \times 10^{-10}$

$1.49 \times 10^{-10}$

$5.88 \times 10^{-11}$

$1.48 \times 10^{-11}$

$7.82 \times 10^{-12}$

$2.49 \times 10^{-12}$

$1.22 \times 10^{-12}$

$7.68 \times 10^{-13}$

$5.67 \times 10^{-13}$ 

